\title{
Os Estados, o sistema-mundo capitalista e o sistema interestatal: uma leitura crítica das contribuições de Immanuel Wallerstein
}

\author{
The states, the capitalist world system and the interstate system: \\ a critical analysis on the contributions of Immanuel Wallerstein
}

MARCO ANTONIO ACCO*

RESUMO: Os Estados nacionais constituem uma das agendas centrais do debate no mundo contemporâneo, uma agenda extensa que gerou importantes abordagens em disputa sobre o ritmo, direção e a profundidade das possíveis transformações dos Estados em curso nas últimas décadas. Este artigo tem por objetivo reconstruir e analisar criticamente os conceitos, atribuições, possibilidades e impasses vividos pelos Estados nacionais encontradas nas formulações de Immanuel Wallerstein. Com este propósito, faremos uma releitura atenta de sua obra, retendo os principais componentes de sua formulação sobre o Estado em suas interações com o sistema mundo capitalista e o sistema interestatal. Parte-se de uma síntese crítica das formulações de Wallerstein sobre sistemas históricos como a unidade de análise correta, as formas históricas desses sistemas, o duplo conceito de capitalismo, de sistema capitalista mundial, de Estado e de sistema interestatal enquanto categorias cruciais de sua abordagem. Tendo por base esses fundamentos, explora-se, então, a análise de Wallerstein sobre o papel dos Estados nacionais nos dias atuais, a crise do sistema mundo que vivemos, assim como as possibilidades e impasses da atuação dos Estados neste contexto. As considerações finais abordam limites e oportunidades legadas por sua desafiadora formulação.

PALAVRAS-CHAVE: Estado; teoria social contemporânea; teoria do estado, sistema mundo; Immanuel Wallerstein.

ABSTRACT: National States are one of the central issues in the contemporaneous debate in the world, an extensive agenda that has generated important approaches in harsh dispute on the pace, direction, and depth of possible transformations of the state in the last decades. This article aims to reconstruct and critically analyze the concepts, attributions, possibilities, roles and impasse experienced by national States in the modern world system as found in the formulation of Immanuel Wallerstein. With this purpose, this article makes a journey through Wallerstein's extensive work, retaining the main components of his formulation

\footnotetext{
* Professor do Departamento de Gestão Pública da Universidade Federal da Paraíba, João Pessoa/PB, Brasil. E-mail: accomarco@gmail.com. Submetido: 20/Julho/2015; Aprovado: 23/Abril/2018.
} 
on the State in its interactions with the capitalist world system and the interstate system. It begins with a synthesis of Wallerstein's formulations on historical systems as the correct unity of analysis, the historical forms of these systems, until the concepts of capitalist world system, State and interstate system as crucial categories. Based on these foundations, then, it explores Wallerstein's analysis on national States today, the contemporaneous crisis of the world-system, as well as the possibilities and dilemmas for the action of national States in this context. The conclusions address limits and opportunities offered by Wallerstein's challenging approach. When national solutions seem to fail around the world, a return to Wallerstein's work and his perspective centered on the capitalist world system may reveal relevant findings.

KEYWORDS: Contemporaneous social theory; world-system; State; Immanuel Wallerstein. JEL Classification: P10; BOO; N40; F00.

\section{INTRODUÇÃO}

Os Estados nacionais têm se mantido no centro da agenda do debate político, econômico e social especialmente nas últimas quatro décadas, não só no Brasil, mas em grande parte dos países e regiões do mundo. Provavelmente nenhuma outra macroinstituição social tem passado por um processo tão intenso, amplo e rigoroso de revisão e questionamento de seus fundamentos, atribuições, falhas, virtudes, capacidades e razões de existir, quanto os Estados nacionais ${ }^{1}$.

Este amplo debate - que deve seguir intenso nas próximas décadas - articula-se em inúmeras agendas e subagendas, todas elas de alta relevância, como por exemplo as questões relacionadas aos recorrentes processos de embates políticos (mais ou menos violentos ou democráticos) para a constituição, tomada, destituição e redefinição do poder de Estados (e de governos) ao redor do mundo (Wimmer, 2013; Leander, 2004; Wallerstein, 2000b); a questão do papel do complexo segurança/violência na estruturação dos Estados modernos e suas transformações no mundo contemporâneo (Leander ,2004; Mann, 1997; Tilly, 1985; Held, et al., 1999; STRANGE 1996); o debate sobre a ascensão e declínio de impérios e Estados hegemônicos e, de modo especial, o debate sobre o declínio dos Estados Unidos, além das similaridades e diferenças em relação aos demais impérios e Estados hegemônicos (Mann, 1997; Wallerstein, 2000b, 2000f; Arrighi, 2008, 1999); a questão do avanço de experiências democráticas em diferentes territórios e os impactos destes processos - muitas vezes contraditórios e certamente não unívocos - na composição, atuação e mesmo redefinição de Estados e governos (Santos, 2002; Held, 2005;

\footnotetext{
${ }^{1}$ Este artigo é uma síntese revisada de parte do capítulo 4 de minha tese de doutorado Para onde vão os Estados nacionais? Perspectivas da teoria social contemporânea sobre as pressões para a transformação dos Estados nacionais na virada para o século XXI, Campinas, 2009, trabalho no qual analiso comparativamente quatro importantes abordagens da teoria social contemporânea sobre o tema, a abordagem neoliberal, a neopluralista globalista, os neoinstitucionalistas históricos e o enfoque neomarxista, tradição na qual, na leitura que faço, Wallerstein se insere.
} 
markoff, 2013; suleiman, 2003, entre outros); as formas e os padrões de interação Estado e capitalismo, especialmente nas relações entre Estados e as grandes corporações econômicas na composição das diferentes estratégias de ativação de mercados (Jessop, 2002; Held et al., 1999; Weiss, 1998; Cable, 1995; Ohmae, 1996; Strange, 1996); a agenda das múltiplas e cambiantes escalas de atuação dos Estados, as intensas pressões para a redefinição das atribuições dos Estados nacionais, relacionadas ao tema da governança global e regional para diversas agendas (Jessop, 2003; Held et al., 1999); a agenda da reconfiguração dos aparatos de bem-estar social, e a possível reconfiguração dos Estados contemporâneos em sua alegada passagem de agente produtor e prestador direto de bens e serviços para agente regulador (Pierson, 1994; Weiss, 1998); a agenda da configuração de uma nova gestão pública (new public management) inspirada nos modos de gestão privada e/ou de uma gestão pública societal ou democrática, inspirada em modos de gestão moldadas pelas formas de participação democrática da sociedade ao longo do ciclo das políticas públicas (Bresser-Pereira, 1998, 1999; Paula, 2005; Pollitt e Bouckaert, 2004); a agenda da capacidade fiscal e das demais capacidades estatais necessárias para fazer frente aos desafios estabelecidos nas atuações dos Estados nas sociedades em que vivemos (Evans, 1995, 2008; Pires e Gomide, 2014).

Além dessas agendas, tivemos o substantivo debate sobre os possíveis impactos do que se tem chamado de globalização sobre a configuração dos Estados nacionais, assim como, no sentido contrário, os impactos das estratégias dos Estados nacionais em reação, suporte ou subordinação à globalização. Esta agenda mobilizou uma série de intelectuais como Ohmae (1990, 1996), Wriston $(1989,1992)$, Cable (1995), Held et al. (1999), Evans (1995, 1997, 2008), Evans, Skocpol e Ruechemeyer (1985), Weiss (1998), Strange (1996), Mann (1997), Jessop (2002), Bresser-Pereira (1998, 1999) e Batista Jr. (1998, 2007), para mencionar alguns dos nomes mais destacados envolvidos num intenso e desafiador debate sobre a agenda das possíveis transformações dos Estados no mundo em que vivemos. Os autores acima mencionados geraram interpretações centradas no Estado, ou centradas na Sociedade, ou mesmo centradas nas relações Estado-Sociedade, com inclinações neoliberais, global pluralistas, céticas à globalização, neorrealistas, neonstitucionalistas, neomarxistas, dos sistemas-mundo, todas com variantes e subvariantes internas, além de formas híbridas de interpretação que combinam aspectos de diferentes tradições intelectuais.

Um dos autores mais provocativos neste extenso e complexo debate tem sido o historiador social norte-americano Immanuel Wallerstein, intelectual que produziu uma análise original sobre os Estados nacionais e o sistema interestatal no âmbito dos três núcleos de formulação que mais lhe ocuparam ao longo de sua trajetória intelectual: a abordagem do chamado sistema-mundo; as questões envolvendo as classes sociais e os movimentos antissistêmicos no contexto dos sistemas-mundo; e também na afirmação de uma via media, como método e como prática, para as ciências sociais melhor compreenderem as dinâmicas do mundo contemporâneo. Parece ser ainda mais relevante revisitar a obra de Wallerstein nos dias 
em que as soluções nacionais para as crises contemporâneas que vivemos no planeta parecem dar claros sinais de esgotamento, e mesmo de paroxismo.

Embora a agenda do Estado não tenha ocupado o centro das investigações intelectuais de Wallerstein, este artigo tem como principal propósito identificar a sua interpretação sobre os Estados nacionais encontrada razoavelmente dispersa em sua extensa obra. Em termos metodológicos, o tipo de análise aqui apresentada busca identificar e analisar criticamente os fundamentos teóricos, os conceitos e os métodos que estruturam e organizam a produção intelectual de Wallerstein, contrapondo-a, nos limites de um artigo, com argumentos e métodos mobilizados por outras abordagens, assim como com a crítica interna de alguns de seus principais constructos.

Este artigo faz um percurso pela obra de Wallerstein, partindo da identificação de suas formulações mais propriamente metodológicas sobre sistemas históricos como a unidade de análise correta a ser considerada para a compreensão da realidade contemporânea, passando pelos atributos que delimitam esta unidade de análise. $\mathrm{Na}$ sequência, serão abordadas as formas históricas dos sistemas (minissistemas e sistemas-mundo, em suas duas variantes, império e capitalismo), para chegar às definições de capitalismo, sistema-mundo capitalista, de Estado e de sistema interestatal. $\mathrm{Na}$ seção final, exploro a análise de Wallerstein sobre os Estados nacionais hoje, a crise do sistema-mundo, os desafios lançados pela onda longa de democratização, assim como as possibilidades e os impasses da atuação dos Estados neste contexto.

\section{SISTEMAS HISTÓRICOS E A DELIMITAÇÃO DAS UNIDADES DE ANÁLISE RELEVANTES - FUNDAMENTOS TEÓRICOS PARA SE ENTENDER O PENSAMENTO DE WALLERSTEIN}

Como ponto de partida, é preciso termos em mente que Wallerstein apresenta a firme perspectiva de lidar com as totalidades sistêmicas da realidade social, e não apenas com partes ou segmentos desta realidade. Para ser mais preciso, as partes devem ser sempre consideradas em estreita conexão, e mesmo subordinação - lógica e histórica - à totalidade sistêmica. O seu ponto de partida metodológico é, portanto, a construção de uma totalidade de longa duração e de longa escala no interior da qual os conceitos tenham sentido. Para o autor, impõe-se metodologicamente a necessidade lógica e histórica de derivar os conceitos e as instituições menos abrangentes, como são as instituições/conceitos de classe, Estado, householding, racismo, cultura, nacionalismo, liberalismo, movimentos antissistêmicos e outros em relação à totalidade sistêmica que lhes confere os atributos e os contornos mais contundentes e decisivos².

\footnotetext{
${ }^{2}$ Como lhe é bastante peculiar, Wallerstein é bastante incisivo sobre a questão: The development of the capitalist world-economy has involved the creation of all the major institutions of the modern world: classes, ethnic/national groups, households - and the 'states'. All of these structures postdate, not antedate capitalism; all are consequences, not cause (Wallerstein, 1984a: 29).
} 
Em termos lógicos e históricos, a economia-mundo capitalista é o ponto de partida para compreender todas as demais instituições do mundo moderno, e não o contrário. De sua perspectiva, o conceito de sistema histórico assegura a unidade de análise mais adequada e, ao mesmo tempo, configura a via media nas ciências sociais, a ser estabelecida pela incorporação, tanto de aspectos $d a$ abordagem dos cientistas sociais nomotéticos (em suas buscas por leis gerais e permanentes do comportamento individual e coletivo), quanto das abordagens idiográficas, em busca das especificidades dos comportamentos associados aos diferentes contextos e casos. A via media a ser buscada no conceito de sistemas históricos apresenta-se como uma síntese dialética em que as totalidades a serem consideradas devem ser suficientemente amplas, em termos de tempo e espaço para escaparem ao fracionamento ad infinitum das narrativas idiossincráticas, mas curtas o suficiente para não se diluírem em leis gerais tão remotas e genéricas que acabam perdendo a capacidade de elucidação e compreensão das ações humanas no mundo real. Em suas palavras: "We must rather stand on the ground of what I shall call the unexcluded middle - both time and duration, a particular and a universal that are simultaneously both and neither - if we are to arrive at a meaningful understanding of reality" (Wallerstein, 2000a: 165).

$\mathrm{Na}$ formulação de Wallerstein, as fronteiras da unidade de análise seriam aquelas definidas pelas lógicas que 'determinam' a maior parte da realidade social. Há, portanto, três questões, interligadas e complementares. Primeira, quais seriam as lógicas que determinam a maior parte da realidade social? Segunda, como identificar que a maior parte da realidade está sendo determinada? E, terceira, como considerar a forma como as governing logics "determinam" a realidade, ou seja, como lidar com as sutilezas que as aspas, presentes em sua formulação original, indicam existir na relação de "determinação"?

Wallerstein responde à primeira questão em termos filosóficos, assumindo que os seus argumentos se fundam a priori num viés materialista, ou seja, nas relações materiais de produção. A sua resposta à segunda se dá em termos heurístico-pragmáticos: os critérios adequados para comporem a unidade de análise são aqueles que impactam na maior porcentagem da ação social, no sentido em que mudanças em seus fundamentos ou parâmetros de funcionamento impactarão imediata $e$ profundamente o funcionamento de outras partes do todo (Wallerstein, 1984: 28).

A resposta à questão da "determinação" é mais complexa, já que Wallerstein busca, a princípio, fugir aos determinismos a priori definidos pelos métodos de análise que, ao terem especificados os parâmetros iniciais, têm suas explicações automaticamente derivadas deste núcleo de pressupostos iniciais. Contudo, a meu ver, as aspas não são suficientes para relativizarem o peso da noção de determinação: as partes, os conceitos ou as instituições, por assim dizer, menores (como os Estados, as classes etc.) são resultantes das lógicas que compõem a totalidade e sempre terão que se reportar a elas. Mesmo que em algum momento possam ganhar alguma autonomia, é uma autonomia atribuída/concedida pelas lógicas, conflituosas e contraditórias, de funcionamento da totalidade, no caso, do sistema-mundo capitalista em que estamos mergulhados e envolvidos desde o século XVI. 
Em termos mais concretos, as unidades de análise (as totalidades sistêmicas) a serem consideradas seriam aquelas definidas no interior de uma determinada divisão do trabalho, de tal forma orgânica e completa que constituem mundos nos quais os vários setores ou áreas são dependentes das trocas econômicas com os outros setores ou áreas para a sua mútua e continuada manutenção. As regras e os procedimentos da divisão do trabalho, portanto, enfeixam o mundo orgânico dos sistemas, perpassando e atribuindo as principais características dos processos econômicos, políticos e socioculturais que se desdobram em seu interior.

A noção de totalidades orgânicas, segundo Wallerstein, não implica que estes sistemas funcionem como máquinas perfeitas, a-históricas e eternas, como pretendem os pensadores que intentam naturalizar as lógicas, comportamentos e racionalidades típicas do capitalismo e dos capitalistas à essência humana. Antes, são resultantes de processos sociais insatisfatórios, contraditórios e conflituosos e, por isso, suscetíveis aos ciclos orgânicos da vida, de nascimento, desenvolvimento e de superação. Alterados os fundamentos ou o modo de funcionamento destes processos integrados de produção, as condições de funcionamento das totalidades sistêmicas entram em crise.

\section{FORMAS HISTÓRICAS DE TOTALIDADES SISTÊMICAS: MINISSISTEMAS E SISTEMAS-MUNDO E O APARECIMENTO DOS ESTADOS NACIONAIS}

De acordo com Wallerstein, ao longo da história humana teriam existido duas modalidades de totalidades sistêmicas, os minissistemas e os sistemas-mundo. Os minissistemas seriam aqueles pequenos agrupamentos tribais organizados com base numa divisão do trabalho orgânica articulada fundamentalmente pelo princípio da reciprocidade (exercida em termos de linhagem e proximidade), que constituiriam uma única entidade política e uma cultura uniforme em seu interior. Dotados, em comparação com os sistemas-mundo, de uma divisão de trabalho pouco complexa e de uma racionalidade pouco expansionista. Os minissistemas, segundo Wallerstein, teriam decaído ou sido absorvidos pelas expansões dos sistemas-mundo, em suas duas variações: os impérios-mundo e a economia-mundo capitalista.

Os impérios-mundo, por sua vez, seriam aqueles sistemas sociais calcados em mecanismos econômicos redistributivos (tributários), encontrados em seus períodos históricos nas grandes civilizações pré-modernas da China, Egito e Roma. Ao terem seu sistema de acumulação interna calcado numa máquina administrativa e militar centralizada e capaz de coletar recursos e administrar territórios com diferentes formações socioculturais, em geral conquistados em guerras e ocupações, os impérios-mundo desintegraram-se, sendo superados por uma forma menos dispendiosa, mais flexível e mais abrangente de divisão do trabalho e de sistema político. Isso porque, quando os impérios-mundo ampliavam seus territórios, eram forçados a

submeterem diferentes culturas e formações políticas a uma unidade política central, com custos crescentes de ocupação e manutenção desses novos territórios. Além disso, as atividades de comércio de longa distância existentes nos impérios-mundo 
permaneceram marginais, submetidas à administração central e restritas ao comércio de mercadorias de luxo, e, deste modo, não determinavam de modo fundamental o destino do império, nem das sociedades por ele abarcadas (Wallerstein, 2000e: 75).

$\mathrm{Na}$ perspectiva de Wallerstein, a transição do feudalismo ao capitalismo teria envolvido antes de tudo (lógica e historicamente) a constituição de uma economia-mundo, ou seja, de uma divisão de trabalho que emergiu no século XVI, cobrindo inicialmente a maior parte da Europa, a partir da transição de um mercado de longa distância, restrito às mercadorias de luxo, para mercados de longa distância agora calcados em mercadorias essenciais para a plena reprodução do sistema-mundo. Estas mercadorias estariam conectadas por circuitos produtivos e distributivos interdependentes, porém dispersos em cadeias mercantis de longa distância que perpassam fronteiras nacionais e que são apoiadas por Estados nacionais, reconhecidos enquanto tal por um sistema interestatal. Na interpretação de Wallerstein, o sistema interestatal, por sua vez, emerge de modo concomitante com a ascensão do capitalismo, e tem como um de seus momentos mais marcantes o Tratado de Westphalia, firmado em 1648.

\section{CAPITALISMO, ESTADO, SISTEMA INTERESTATAL E HEGEMONIA}

Partindo do conceito de capitalismo, fundamental para o seu sistema argumentativo, é importante enfatizar que Wallerstein apresenta ao menos duas definições para esta categoria central. A primeira (definição 1) conceitua o capitalismo como um modo de produção visando à obtenção de lucros no mercado (Wallerstein, 2000o: 84). Embora concisa, esta definição apresenta aspectos importantes que a distinguem de outras definições de capitalismo ${ }^{3}$. Esta definição oferece a Wallerstein um parâmetro teoricamente mais seguro para identificar a origem histórica do capitalismo do que, por exemplo, a definição de Marx, vinculada à generalização da forma assalariada do trabalho (a transformação do trabalho humano em mercadoria). Com base nesta definição bastante simples, Wallerstein pôde retroceder até o século XVI e identificar o surgimento de um capitalismo agrícola com a produção, razoavelmente generalizada no continente europeu, de mercadorias inicialmente agrícolas para serem comercializadas para a obtenção de lucro nos mercados, mesmo que a força de trabalho assalariada utilizada em suas respectivas cadeias de produção e comercialização tenha sido apenas uma das formas (e, por um longo período, não a mais importante) de força de trabalho empregadas no

\footnotetext{
${ }^{3}$ Este não é o lugar para explorar os significados destas definições e as distinções que se apresentam, por exemplo, entre Wallerstein e Braudel, Marx ou Schumpeter no tocante à definição do capitalismo. Schumpeter, por exemplo, define o capitalismo como sendo, "pela própria natureza, uma forma ou método de mudança econômica, e não apenas nunca está, mas nunca pode estar, estacionário. [...] $O$ impulso fundamental que inicia e mantém o movimento da máquina capitalista decorre dos novos bens de consumo, dos novos métodos de produção ou transporte, dos novos mercados, das novas formas de organização industrial que a empresa capitalista cria" (Capitalismo, socialismo e democracia, p. 112)
} 
processo de produção e comercialização. Ademais, indaga Wallerstein, de que modo o trabalho poderia ser mais explicitamente uma mercadoria do que na forma de trabalho escravo?

Neste sentido, Wallerstein é bastante explícito em sua crítica a Marx e a alguns marxistas que, assim como Adam Smith e muitos liberais, teriam assumido a definição de capitalismo associado ao livre fluxo de fatores de produção como outra característica do capitalismo, agora concorrencial, entendendo-se por livre a disponibilidade desses fatores para compra e venda nos mercados e por concorrencial a presença de um grande número de competidores e a inexistência de interferências políticas nos mercados (Wallerstein, 2000i: 141).

O capitalismo, portanto, não pode ser confundido com a fábula liberal da livre concorrência, do livre fluxo dos fatores, da não interferência dos Estados, da inexistência de cartéis e monopólios ou a existência de relações de trabalho não assalariadas como formas estranhas ao capitalismo. Assim, ao invés de concorrencial, o capitalismo (definição 2) deve ser compreendido como o sistema-mundo onde vigora a liberdade parcial dos fatores de produção nos mercados $e$ marcado pelas interferências seletivas da máquina política no mercado (Wallerstein, 2000d: 260). Essas duas definições serão retomadas ao longo deste artigo.

A economia-mundo capitalista que emergiu na Europa caracterizou-se por envolver múltiplas polities e culturas numa única divisão de trabalho, sem a necessidade de constituir uma unidade central de dominação política. Este atributo configurou uma enorme vantagem estabilizadora para o novo sistema-mundo em expansão já que ele conseguiu conviver com diferentes regimes políticos por onde a sua divisão de trabalho se estendeu. Enquanto um modo de produção e de acumulação, o capitalismo fundamenta-se numa incessante e insaciável acumulação de capital. É isso que mobiliza a sua necessidade de incorporação expansiva de novos territórios, novos segmentos, novos públicos e novas esferas à sua lógica de acumulação.

Ao ampliar sua base territorial para o mundo todo, a economia-mundo capitalista também expande o seu sistema interestatal de apoio ao processo de acumulação: da perspectiva de Wallerstein, os Estados soberanos, tal como os conhecemos hoje num número próximo a duzentos, tiveram suas principais características definidas por este sistema, e conquistaram sua legitimidade por uma combinação de autoproclamação e, principalmente, de reconhecimento político pelos seus pares, Estados também soberanos e também configurados pela economia-mundo.

O moderno sistema mundial é constituído, portanto, por uma economia-mundo em incessante expansão, cuja divisão de trabalho exibe uma tensão centro-periferia baseada na troca desigual; e por uma superestrutura política constituída por Estados nacionais formalmente soberanos, reconhecidos e constrangidos por um sistema interestatal (Wallerstein 2000d: 254). Ideologicamente, o sistema organiza-se fundamentado em duas premissas básicas: em termos econômicos, está assentado na premissa do livre fluxo dos fatores de produção, que reveste uma estrutura econômica marcada tanto pela expropriação individual, racial, sexista e de classe, quanto por uma divisão axial do trabalho social entre centro e periferia. Politica- 
mente, funda-se na premissa da soberania isonômica entre os Estados nacionais, assertiva que encobre expressivas assimetrias de poder entre os Estados. De fato, os Estados não são nem iguais, nem plenamente soberanos. O sistema interestatal, ao mesmo tempo em que é fundamental para reconhecer os Estados, delimita seu campo operacional, cerceia seu poder de atuação autônoma e soberana - o que valeria até mesmo para os Estados mais poderosos. Deste ponto de vista, o sistema interestatal é um grande complemento à economia-mundo capitalista por manter os Estados nacionais dentro de limites aceitáveis de interferência no mundo econômico (Wallerstein, 2000d).

No nível bastante abstrato em que Wallerstein aborda as interferências dos Estados nacionais nos mercados, ele as define como aquelas intervenções orientadas para ampliar a acumulação capitalista. Esta é a seletividade da ação estatal. Novamente uma definição sucinta que precisa ser mais bem considerada e sobre a qual há pelo menos quatro agrupamentos de importantes questões: (a) como se dá a relação entre as classes e os Estados, em particular entre a burguesia e os Estados nacionais, e a questão subjacente da autonomia dos Estados nacionais em relação às classes dominantes; (b) quais são os tipos de interferências dos Estados consideradas mais relevantes para a acumulação capitalista; (c) a questão da soberania dos Estados nacionais no sistema interestatal; e (d) qual a relação entre os movimentos ideológicos mais abrangentes na economia-mundo capitalista, o liberalismo e o trabalhismo-socialismo, e as suas interações com os Estados nacionais.

\section{a) Classes e Estado na economia-mundo}

Wallerstein é bastante contundente ao afirmar que, desde o início do capitalismo, as classes dirigentes teriam se voltado para os Estados nacionais como forma de atingir o máximo de lucratividade para as suas atividades/setores, buscando ou liberar-se das restrições não mercantis existentes ou criar novas restrições que as livrassem dos riscos do livre mercado. Os Estados são, portanto, created institutions reflecting the needs of class forces operating in the world-economy (Wallerstein, 1984: 33). Deste modo, a burguesia tem buscado to avoid the normal operation of the market whenever it does not maximize their profit. The attempts of these actors to use non-market device to ensure short-run profits makes them turn to the political entities which have in fact power to affect the market - the nation states (Wallerstein, 2000e: 85).

Wallerstein considera esta inclinação da burguesia em recorrer aos Estados nacionais como uma curiosa anomalia, já que esta orientação não é condizente com os seus papéis econômicos objetivos enquanto classe gerada pela economia-mundo capitalista. A mesma anomalia acometeria o proletariado, que, embora tenha formado a sua consciência de classe mais tarde que a burguesia, também teria recorrido aos Estados ao buscar os mecanismos mais prontamente disponiveis para melhorar as condições de segmentos das classes trabalhadoras (Wallerstein, 1984: 35). Note-se que estes argumentos parecem indicar uma espécie de essência objetiva não 
cumprida dos interesses de classes que, de forma distorcida, colocam os Estados nacionais, e não o sistema-mundo capitalista, no centro das suas disputas.

Afirmar que os Estados nacionais buscam atender aos interesses do capital não significa dizer, afirma Wallerstein, que as máquinas estatais sejam marionetes da burguesia. Isso por duas razões básicas. Primeiro, porque qualquer instituição, uma vez criada, desfruta de certa autonomia em relação àqueles que as criaram pela simples razão delas constituirem um corpo de dirigentes e de funcionários cujas carreiras e interesses são beneficiados pelo próprio fortalecimento continuado da instituição (Wallerstein, 2000e: 88). Segundo, ao longo do processo de consolidação dos Estados foram sendo assumidos certos compromissos constitucionais que limitam a autonomia tanto das classes dirigentes em exercer suas vontades livremente sobre os Estados, como a dos Estados tomarem as decisões que bem entenderem, e no tempo que desejarem, no sentido de maximizar a acumulação capitalista. Além disso, Wallerstein sustenta que não é necessário que os burgueses ocupem diretamente postos dentro da máquina estatal para exercerem as suas vontades e necessidades. Basta para isso que moldem as instituições que influenciam os Estados e que defendem os seus interesses, uma visão bastante arguta sobre as formas de lobby e influência no sistema político contemporâneo.

\section{b) As intervenções dos Estados na economia-mundo capitalista}

No confronto de classes, a burguesia tem sido hábil em assegurar que os Estados implementem as ações necessárias para aprimorar a acumulação. De acordo com Wallerstein, estas ações têm consistido em: consolidar os mecanismos formais necessários para assegurar a apropriação da mais-valia; garantir os direitos de propriedade; proteger os capitalistas da competição com outros capitalistas e; protegê-los das classes trabalhadoras (Wallerstein, 1984: 34). As intervenções dos Estados, além de propiciarem o avanço do processo de acumulação, devem apresentar custos de interferência menores que os ganhos que elas tragam, e também devem considerar que [...] interference is always in favor of one set of accumulators as against another set, and the latter will always seek to counter the former (Wallerstein, 2000d: 260).

Há sempre, portanto, ganhos e perdas a serem mediados, colocando os Estados numa posição de grandes máquinas de contabilização e compensação das lucratividades e perdas setoriais. Duas observações. A primeira é que as intervenções dos Estados são representadas por Wallerstein como um jogo no qual os benefícios de alguns significarão perdas para outros grupos e/ou classes; parece não haver possibilidade para aquele tipo de solução em que alguns burgueses ganham mais e outros menos, mas todos ganham algo. A segunda é que parece não haver dúvidas sobre quais as interferências mais adequadas para a maximização da acumulação devem ser implementadas pelos Estados nacionais: parece não haver espaço entre as necessidades dos capitais e dos capitalistas e a atuação dos Estados. Sobre esta dimensão parece operar uma mão invisível guiando as interferências dos Estados rumo aos interesses do capital, em especial de suas frações mais poderosas. Contu- 
do, estudos em geral institucionalistas como os de Evans e Weiss (1998) têm demonstrado haver uma distância (nada desprezível) entre o que os Estados deveriam fazer em termos ideais, e o que efetivamente fazem ou conseguem fazer. Até porque os Estados encontram-se, como o próprio Wallerstein argumenta, em posições distintas nas cadeias de valor centrais, periféricas ou semiperiféricas do sistema-mundo.

\section{c) Soberania e sistema interestatal}

Do ponto de vista da soberania dos Estados nacionais exercerem suas vontades no plano mundial, como já indicado, o que define os Estados nacionais modernos é que seus movimentos são delimitados e acomodados dentro do sistema interestatal constituído pelo sistema-mundo capitalista. Os Estados não são, nem podem ser, nem autônomos, nem soberanos, nem uma instituição total fechada em si.

Um aspecto decisivo desta abordagem é a sua rejeição frontal às premissas dos autores realistas como Hans Morgenthau (2003) e Stephen Walt (2002), entre outros, que consideram o sistema interestatal fundado num estado de anarquia e imprevisibilidade permanente no qual os Estados podem alegadamente agir conforme lhes interesse agir. Antes, ao contrário, sustenta Wallerstein, os Estados nacionais apresentam um padrão de comportamento como seguidores dos parâmetros delimitados pelo sistema interestatal, em que as atuações autônomas são apenas exceções extemporâneas dentro de uma ordem bastante institucionalizada. Em suas bem conhecidas palavras:

We are so used to observing all the things states do that constitute defiance of other states that we do not stop to recognize how few these things are, rather than how many. We are so used to thinking of the interstate system as verging on anarchy that we fail to appreciate how rule-ridden it is. Of course, the "rules" are broken all the time, but we should look at the consequences - the mechanisms that come into play to force changes in the policies of the offending states. Again, we should look less at the obvious arena of political behavior, and more at less observed arena of economic behavior. (Wallerstein, 1984: 33)

Esta característica do sistema interestatal moderno é tão marcante, que mesmo a tão temida Guerra Fria entre as duas superpotências opostas não teria passado de uma coreografia de passos bem ensaiados.

Outro aspecto relevante no sistema-mundo capitalista é que a sua expansão implica a incorporação de periferias e semiperiferias às lógicas dominantes do centro. Os territórios incorporados à divisão econômica e social do trabalho da economia-mundo capitalista, sob jurisdição formal de algum Estado nacional, não mais detém autonomia econômica. Ao serem incorporados às cadeias produtivas e distributivas da economia-mundo capitalista, esses territórios passam a integrar o sistema, sofrendo e/ou se beneficiando dos seus ritmos e ciclos. Os seus Estados 
nacionais, invariavelmente, também passam por algum tipo de adaptação às lógicas dominantes.

Os Estados nacionais dos novos territórios incorporados, como o brasileiro, assevera Wallerstein, operam basicamente no sentido de facilitar tanto a periferi$z a c ̧ a ̃ o$ dos processos de produção na região, como garantir os fluxos de mais-valia dessas para as regiões centrais via sistema de trocas desiguais e outras (Wallerstein, 1984). Mais, o fortalecimento dos aparatos estatais nas regiões centrais "has as its direct counterpart the decline of the state-machineries in peripheral areas" (Wallerstein, 2000e: 88). Nesta geoeconomia com implicações políticas, os países semiperiféricos alcançam este status mais por razões políticas do que econômicas: formam, como as classes médias, um colchão de absorção dos conflitos entre a periferia e o centro, ao mesmo tempo em que rompem com a uniformidade das regiões periféricas, já que são tanto expropriados pelas regiões centrais como expropriadores de regiões mais periféricas. De acordo com Wallerstein, por volta de meados do século XVII as três posições estruturais (centro, periferia e semiperiferia) da economia-mundo já teriam se estabilizado, com poucas alterações desde então (Wallerstein, 2000e; 1984: 86).

\section{d) Liberalismo e Estado liberal}

Desde cedo os capitalistas que operavam nos mercados de longa distância perceberam que a obtenção do lucro máximo somente era possível por meio de algum grau de monopólio, e que esta situação privilegiada era mais facilmente mantida com a ajuda dos seus Estados nacionais. Como lembra Wallerstein, o livre mercado gera uma condição de operações de mercado que propiciam lucros reduzidíssimos, absolutamente insuficientes para alavancar qualquer expansão mais relevante. $\mathrm{O}$ capitalismo enquanto tal é simplesmente insustentável se adotasse a apologia que Adam Smith fez do laissez-faire, laissez-passer.

A grande construção ideológica da economia-mundo capitalista não viria de Adam Smith, mas de uma resposta mais consistente aos movimentos deflagrados durante e após a Revolução Francesa, de 1789, uma resposta que buscou conciliar os interesses dos capitalistas na construção de suas posições tendentes a monopólio e que acomodassem - sob seu viés de classe - os impulsos democráticos e de mudança social colocados em primeiro plano, e de modo irreversível, pelo movimento de 1789 .

Ao mesmo tempo em que buscou acalmar os impulsos revolucionários das camadas populares, o liberalismo que vigorou tratou de afastar o Estado monárquico de muitas frentes de decisão, fortalecendo a perspectiva da eficácia da máquina do Estado e colocando os Estados no epicentro daquilo que Wallerstein chama de reformismo racional. Perceba-se que aqui também Wallerstein confere o vetor da mudança à ideologia liberal e aos seus principais promotores, os capitalistas. A geocultura da burguesia que emergiu após a Revolução Francesa tratou de moldar e domesticar as pressões das dangerous classes, convertendo-as num programa racional de reformas conduzidas pelos Estados dos países centrais. A lenta e controlada expansão do sufrágio universal, ao lado da também lenta ascensão do 
welfare state, representaram conquistas expressivas para os trabalhadores, principalmente para os estratos médios da sociedade. O "pacote" liberal para os países centrais só ficou completo com a criação da identidade nacional, a variável que assegurou que as classes perigosas não aprofundassem as possibilidades oferecidas pelas concessões do sufrágio e do Estado de bem-estar. O que este pacote liberal ofereceu para as dangerous classes dos países centrais foi principalmente esperança - hope that the gradual but steady reforms promised by liberal politicians and technocrats would eventually mean betterment for the dangerous class (Wallerstein, 2000a: 460).

Contudo, o apaziguamento das classes perigosas nos países centrais veio acompanhado pela proliferação de novas classes perigosas, as forças populares no resto do mundo, o que gerou a busca pela aplicação de um programa similar de reformas no plano do sistema interestatal. Na perspectiva do autor em questão, o princípio da autodeterminação dos povos teria servido como equivalente, no plano internacional, ao sufrágio universal, enquanto a perspectiva de desenvolvimento econômico das nações subdesenvolvidas seria o equivalente ao Estado de bem-estar social (Wallerstein 1999:29).

\section{O ESTADO HOJE: CRISE DO CAPITALISMO, DEMOCRATIZAÇÃO E DESLEGITIMAÇÃO DO ESTADO}

Como temos visto, a abordagem de Wallerstein interpretou o capitalismo como um sistema-mundo que, desde o seu início, buscava abarcar o globo com sua divisão de trabalho, suas cadeias mercantis e, principalmente, com sua racionalidade altamente expansiva e envolvente. A globalização ou os efeitos de uma economia globalizada não são, portanto, nenhuma novidade para a abordagem do sistema-mundo. Antes pelo contrário, o que Wallerstein tem argumentado é que o sistema-mundo capitalista é um assunto primordialmente das forças econômicas que operam em escala mundial e não de Estados, classes ou instituições nacionais. Deste modo, os processos e os acontecimentos devem ser compreendidos de "cima", desde as lógicas e contradições do sistema-mundo, e não a partir das sociedades nacionais, como se estas fossem unidades de análise adequadas. Não, este não seria o melhor caminho; para Wallerstein, ao contrário, este é um caminho fútil (Wallerstein, 2000c: 125).

Contudo, como indiquei anteriormente, Wallerstein apresenta pelo menos duas definições de capitalismo, uma mais concisa, e a segunda em que os Estados nacionais, "subordinados" aos imperativos do sistema interestatal, integram a ratio da economia-mundo capitalista, sendo decisivos para a maximização da acumulação, para liberar grupos de capitalistas das agruras do livre mercado, para protegê-los das classes perigosas, e para serem o epicentro da realização prática do programa para acalmar as dangerous classes. Também seriam importantes para cumprir a segunda leva do pacote liberal orientado para os países em desenvolvimento.

Deste ponto de vista, então, considerando a enorme agitação político-intelec- 
tual em torno da chamada globalização e do propalado declínio dos Estados nacionais, o que estaria acontecendo com o capitalismo e com os Estados nacionais na virada para o século XXI? Tendo-se em mente o esquema conceitual montado por Wallerstein, as cadeias produtivas das mercadorias estariam passando por alguma transformação mais expressiva no período atual? Há algo de efetivamente novo provocado pela chamada revolução informacional ou pela alegada ampliação nos indicadores econômicos comumente associados à globalização? O que estaria acontecendo, enfim, com a economia-mundo capitalista e com os Estados nacionais nas últimas três décadas do século XX e, considerando a perspectiva das ondas longas, quais os cenários que se projetam para os próximos 25 a 50 anos?

Wallerstein recusa frontalmente a tese de que algo de novo e expressivo estaria ocorrendo na cadeia de mercadorias e na divisão do trabalho nos últimos trinta anos que pudesse caracterizar o advento da tão propalada globalização. Do mesmo modo, "none is likely to occur because of the so-called information revolution" (Wallerstein, 1999: 21), tão central para abordagens neoliberais como as de Wriston, Cable e Ohmae. As mudanças em curso não seriam suficientes nem mesmo para caracterizar uma nova fase de expansão da economia-mundo; a expansão recente não corresponderia a algo comparável, nem em magnitude, nem em alterações nas cadeias de mercadorias.

A afirmação de que a expansão do capitalismo atingiu a sua geografia máxima é um dos seus principais fundamentos para a caracterização da crise estrutural em que o capitalismo estaria mergulhado, a despeito de possíveis ciclos de recuperação no futuro. A partir de uma compilação de suas análises, é possível identificar ao menos onze contradições ou limitações estruturais e de longa duração, que se desdobram de modo razoavelmente concomitante, e que impediriam um ciclo de recuperação consistente e duradoura do sistema-mundo capitalista. Nos estreitos limites de um artigo, farei breves apontamentos a essas tendências limitantes do capitalismo identificadas pelo autor em análise.

A primeira está relacionada à já mencionada expansão máxima da geografia capitalista, em que todos os espaços geográficos para a exploração capitalista já teriam sido incorporados à sua lógica há mais de um século. Contudo, esta proposição é verdadeira apenas num plano abstrato, considerando-se a possibilidade de o capitalismo ainda explorar/exaurir vastos territórios como a Amazônia, o Cerrado e o pré-sal brasileiros, amplas regiões da África, da Oceania, da Ásia, dentre outras, além do fato histórico inconteste de que territórios e recursos podem mudar de mãos e de tecnologias de exploração. A geografia econômica é cambiante e ainda reserva espaços de avanço.

A segunda estaria relacionada à exaustão progressiva do processo de "mercantilização de tudo", portanto, um contexto em que a incorporação de novos produtos aos mercados seria marginal, insuficiente para sustentar um novo e promissor ciclo de crescimento. Teria o capitalismo esgotado sua capacidade de gerar produtos inovadores, e estas inovações conseguirem constituir um novo ciclo de crescimento? Trata-se, naturalmente, de questões de resposta impossível neste espaço, mas parece ser mais plausível aceitar a resposta de que o capitalismo segue geran- 
do produtos inovadores, mas não necessariamente consegue estabelecer um novo ciclo consistente e duradouro de crescimento. Os ciclos de crise recentes e de incapacidade de gerar recuperações sustentáveis parecem revelar uma intensificação no ritmo das crises sistêmicas mundiais, um mal-estar civilizacional com o capitalismo e seus paroxismos, especialmente diante do aumento das desigualdades, os sinais de colapso ambiental e a difusa percepção de insegurança crescente em múltiplas dimensões relevantes do mundo da vida.

Uma terceira limitação estaria relacionada ao encerramento do processo de urbanização/desruralização do mundo, com a consequente exaustão da fonte primordial de abastecimento de força de trabalho barata e abundante com que o capitalismo pôde contar. Trata-se, objetivamente, de uma restrição estrutural, desde que o mundo rural encolhe e a urbanização é inquestionável em todas as regiões do mundo. Contudo, esta incontestável concentração urbana tem sido compensada, ao menos parcialmente, com as múltiplas formas de precarização das relações trabalhistas, individualização das responsabilidades e fragilização dos sindicatos e organizações trabalhistas, além da incorporação de inovações tecnológicas que dispensam sistematicamente trabalhadores. Enquanto, de um lado, as empresas conquistam certas garantias contra a concorrência, elas oferecem aos trabalhadores o trabalho mal remunerado, intermitente, e um cenário de competição extrema entre os trabalhadores, inclusive entre os que se pensam empresários de si.

A quarta está relacionada à forte tendência de desequilíbrios populacionais entre o Norte e o grande Sul mundial, fenômeno que provoca pressões contraditórias para os Estados nacionais, pois se de um lado estes fluxos migratórios poderiam oferecer a mão de obra desqualificada necessária, por outro, provocam pressões sobre os custos de manutenção dos Estados de bem-estar. Trata-se de uma tendência em curso, com sinais evidentes de aumento da vigilância interna de grupos sociais não plenamente incorporados nos países, expulsões de alguns contingentes (como a ameaça que paira sobre os milhões de imigrantes sem documentos nos EUA sob Trump), recrudescimento das regras de migração, a criação de campos de concentração de imigrantes, além de ameaças de muros, nesta que já era a dimensão reconhecida como a menos bem-sucedida da globalização, como demonstrado por Held e associados (1999).

Uma quinta contradição está relacionada à exaustão ambiental e à incapacidade crescente de os capitalistas continuarem transferindo os custos da degradação ambiental de sua produção e acumulação para a natureza, para a sociedade e para os Estados. Notadamente, esta parece ser uma tendência incontestável, ainda sem freios, cujos efeitos são potencialmente devastadores (Marques, 2015).

A sexta está relacionada ao agudo crescimento das disparidades, internas, mas principalmente globais, de renda e de acesso a condições mínimas de cidadania, aspecto que provocaria tanto pressões para o aumento da migração sul-norte para zonas centrais, como a perda da esperança da população com as soluções engendradas pelos Estados nacionais e pelos movimentos antissistêmicos. Uma tendência crua, indisfarçável de aumento da concentração das riquezas, ao lado da perda de esperança por parte da população nos arranjos de Estados de 
bem-estar, além de crescente sensação de insegurança parecem ser partes do mesmo lado da moeda.

Uma sétima tendência corresponde à incapacidade crescente dos Estados oferecerem condições de segurança interna e externa para suas populações, tanto para as camadas ricas como para as pobres. Embora os dados mundiais possam mandar sinais contraditórios, a percepção de insegurança parece disseminar-se, talvez exceto em poucas regiões do planeta, mesmo que alguns indicadores de violência tenham declinado (Laidler, 2015, por exemplo), enquanto Strange (1996) corrobora com importantes evidências a hipótese do declínio da capacidade dos Estados lidarem com formas de crime organizado, projetando a consolidação de arranjos semi-institucionalizados entre Estados e formas de crime organizado (também Tilly, 1985).

Uma oitava tendência estaria relacionada à crescente instabilidade financeira internacional, tanto um efeito quanto uma causa da crise sistêmica. Como já indicado, os três setores fundamentais para a economia-mundo capitalista na perspectiva de Wallerstein - agroindustrial, comercial e financeiro - apresentam sinais de declínio setorial de suas produtividades, culminando com períodos de aparente predomínio do capital financeiro, aspecto que seria incompatível com o próprio capitalismo, considerando que este sistema histórico é antes de mais nada um modo de produção e depende sobremaneira dos setores produtivos para a maior parte da mais-valia gerada pelo sistema. Até onde o capitalismo pode conviver com esta hegemonia do seu subsistema financeiro está longe de ser uma questão definida, até porque as formas de junção entre os capitais financeiros e produtivos são uma realidade do mundo corporativo contemporâneo.

As nona e décima contradições estão fortemente interligadas, e consistem, de um lado, no processo de democratização em curso no mundo e, de outro, na perda de confiança das populações nas alternativas engendradas pelo Estado liberal e pelos movimentos antissistêmicos - quando estes chegam ao "controle" de Estados nacionais - para proporcionarem melhores condições de vida às populações. A perda de fé num futuro melhor seria, no contexto atual, o grande pano de fundo para a grande virada contra os Estados que se observa hodiernamente em diversos lugares. Ou, como afirma Wallerstein: "No one ever really liked the state, but the great majority had permitted its powers to grow ever greater because they saw the state as the mediator of reform. But if it cannot play this function, then why suffer the state?" (Wallerstein, 2000c: 385)

A democratização, por sua vez, é um processo mais fundo e difuso, mas que tem traduções práticas ligadas ao grande problema estrutural do capitalismo: as exorbitantes desigualdades. Deste modo, boa parte da população traduz democracia fundamentalmente em demanda por um nível de renda razoável (via emprego ou pensão), acesso à educação e acesso a serviços de saúde de qualidade. Considerando que conquistar estes três pequenos acessos representa custos que praticamente nenhum Estado consegue arcar, Wallerstein conclui que o desfecho das pressões por mais democracia implicam a radically different system of distribution of the world's resources than we have today (Wallerstein, 2000c: 386), ficando em aberto 
se a democracia será capaz de domar o capitalismo rumo a este novo sistema de distribuição dos recursos mundiais.

Finalmente, o último fator estrutural que impediria uma recuperação glorieuse do capitalismo está associado à crise profunda em que os Estados liberais estariam mergulhados. Esta crise apresenta pelo menos quatro frentes principais. De um lado, temos a crise de legitimidade dos Estados liberais nos países do centro e da periferia. De outro, os Estados encontram-se açodados por aumento e diversificação de demandas, resultantes tanto do aumento das pressões democráticas por renda, saúde e educação, quanto pelas demandas da acumulação capitalista (infraestrutura, compras, subsídios e remuneração do capital), aspectos que induzem os Estados a níveis insustentáveis de endividamento. Como resultado, e por outro lado, os Estados nacionais encontram-se mergulhados em crises fiscais estruturais, nas quais medidas como a redução de gastos, downsizing, contracting out, reengenharias e outras que compuseram o pacote recente de ajustes dos Estados não passam de paliativos sem efeitos significativos. As soluções no âmbito do sistema-mundo envolvem reformas estruturais, com soluções inconciliáveis: à direita, empurrar para fora dos serviços públicos de bem-estar expressivos contingentes populacionais e ampliar a privatização e financeirização de tudo; e à esquerda, agendas como a auditoria e revisão do endividamento público e sobre quem recai o seu fardo, além da tributação progressiva sobre os mais ricos e a retomada dos programas de bem-estar e de regulação e redistribuição. A quarta frente da crise dos Estados está associada ao escopo limitado de atuação dos Estados nacionais ante a escala global dos problemas a serem enfrentados e das soluções a serem construídas. Wallerstein é completamente cético à perspectiva de afirmação de um welfare state global, nem cogita a possibilidade de organismos internacionais conseguirem construí-lo num futuro próximo.

De forma coerente com a sua arquitetura conceitual, Wallerstein sustenta que a globalização "is not in fact significantly affecting the ability of the states to function, nor is it the intention of large capitalists that it do so" (Wallerstein, 1999: 32). Mas, se não ocorreu qualquer alteração significativa nas estruturas da economia do sistema econômico mundial, o que, então, na perspectiva do autor, tem provocado a perda da soberania e da capacidade dos Estados nacionais?

The states are, however, for the first time in 500 years, on a downward slide in terms of their sovereignty, inward and outward. This is not because of a transformation of the world-economic structures but because of a transformation of the geoculture, and first of all, because of the loss of hope by the popular masses in liberal reformism and its avatars on the left. (Wallerstein, 1999: 32)

E exatamente em decorrência do fato de que a existência de um Estado relativamente (ou funcionalmente) soberano interna e externamente no âmbito de um sistema interestatal é um pilar fundamental para a economia capitalista mundial, 
If it falls, or seriously declines, capitalism is untenable as a system. I agree that it is in decline today, for the first time in the history of the modern world-system. [...] The state still matters - to the entrepreneurs above all. And because of the declining strength of the states, the transnationals find themselves in acute difficulty, faced as they are with a long-term profits squeeze for the first time and with states that are no longer in a position to bail them out. (Wallerstein, 1999: 33)

Os próximos 25 a 50 anos serão, portanto, uma era de transição, um período de bifurcações e crises. Contudo, mesmo em tempos de caos, as operações fundamentais da economia-mundo capitalista seguirão normalmente - empresas seguirão buscando maximizar seus rendimentos; os capitalistas continuarão buscando suporte junto aos Estados; Estados continuarão competindo entre si para serem os principais locais de acumulação de capital etc. Na leitura de Wallerstein, o que irá mudar de modo mais substancial no próximo meio século é que não haverá um discurso ideológico nitidamente dominante, e que os Estados perderão sua legitimidade, aumentando ainda mais as dificuldades de desempenharem as funções que são esperadas deles pela ratio do sistema-mundo.

\section{CONSIDERAÇÕES FINAIS}

Como vimos, Wallerstein está preocupado em fundar uma teoria social que apresente uma interpretação mundial para a sociedade moderna, para a qual os imperativos das cadeias de produção e de valorização da economia-mundo capitalista são os determinantes a serem detectados e mobilizados para o devido entendimento dos fenômenos sociais contemporâneos. A unidade de análise a merecer a atenção do pesquisador social deve ser, de sua perspectiva, a economia-mundo capitalista, a partir da qual as narrativas sobre as demais categorias e sobre as diferentes realidades "nacionais" devem ser construídas.

Em sua formulação, os Estados nacionais são categorias derivadas do sistema-mundo capitalista que, de forma complementar às cadeias de valor da economia-mundo. O capitalismo constituiu o seu sistema interestatal, ao qual todos os Estados, mesmo os mais poderosos, devem sua legitimidade e devem, portanto, se reportar. Disso decorre que, diferentemente do que concluem os teóricos do realismo convencional das relações internacionais, Wallerstein identifica muito mais concordância e alinhamento entre os países dentro do sistema interestatal da economia-mundo capitalista do que propriamente desconfianças, conflitos e mudanças. Definidas as hegemonias da Holanda, da Inglaterra e dos Estados Unidos, a economia-mundo segue seu rumo normal, que repõe movimentos cíclicos de acumulação e crise e que, em seus movimentos de longa duração, tendem à superação ou ao declínio, exatamente como ocorre com qualquer outro organismo vivo, particularmente um que engendra tamanha ordem de contradições.

Como procuramos demonstrar, Wallerstein opera com dois conceitos de capita- 
lismo, um mais conciso, em que o capitalismo é definido simplesmente como um modo de produção visando à obtenção de lucros no mercado, e um segundo, em que os Estados aparecem complementando o funcionamento da economia-mundo capitalista. Argumento que a definição mais concisa de capitalismo não se sustenta, uma vez que este conceito só começa a fazer pleno sentido prático depois da complementação que Wallerstein opera em sua segunda definição, quando passa a atribuir relevância para as interferências seletivas dos Estados, o Estado, portanto, como pilar fundamental do capitalismo. Esta não é uma incorporação como outra qualquer, mas uma que, para mantermos a sua terminologia, altera as cadeias de valor do capitalismo.

Contudo, mesmo nesta segunda formulação, Wallerstein manteve os Estados como "variáveis dependentes" do sistema-mundo, de modo que há uma recusa em sua abordagem em observar os papéis estruturais dos Estados nacionais para o funcionamento do capitalismo em seus fundamentos micro, meso e macroeconômicos, políticos, institucionais e, talvez, sobretudo, para a coesão e reprodução social em sociedades complexas - e isso nas diversas escalas possíveis de sua ação, do local ao mundial, passando pelas variadas formas de nacional e regional. Sua abordagem da economia-mundo mantém-se fiel a um nível de abstração que não contempla adequadamente os Estados, e que entra mesmo em contradição com o seu próprio conceito da unidade de análise relevante para o pesquisador.

Como uma crítica interna aos seus argumentos, se considerarmos a definição de Wallerstein sobre os critérios que compõem uma totalidade sistêmica, definidos como aquele conjunto de lógicas que determinam a maior parte da realidade social, fica impossível abstrair os Estados nacionais como componentes relevantes (ou determinantes) na construção das lógicas que definem as diferentes realidades do sistema-mundo capitalista. Para uma crítica externa, recorro a Fernand Braudel, para quem, em diálogo direto com I. Wallerstein:

"[...] no centro da economia-mundo aloja-se sempre, forte, agressivo, privilegiado, um Estado fora de série, dinâmico, ao mesmo tempo temido e admirado. Já é o caso de Veneza no século XV; da Holanda no século XVII, da Inglaterra no século XVIII e mais ainda no século XIX; e dos Estados Unidos atualmente.” Poderiam esses governos no centro deixar de ser fortes? Immanuel Wallerstein, prossegue Braudel, "deu-se o trabalho de provar que não [...], como se a posição central, por si só, não criasse e não exigisse também um governo eficaz.[...]" Para um pouco adiante, concluir: "Isso não impede, em contrapartida, que estes governos 'centrais' sejam mais ou menos dependentes de um capitalismo precoce, já com dentes crescidos. O poder é partilhado entre eles e ele. Nesse jogo, sem sucumbir a ele, o Estado mergulha no próprio movimento da economia-mundo. Servindo aos outros, servindo ao dinheiro, ele serve a si mesmo". (Braudel, 1996: Vol. 3: p. 42)

Interpreto esta recusa em buscar compreender de modo mais acurado a importância dos Estados capitalistas contemporâneos tanto como uma necessidade de preservar as noções fortes de seu esquema de análise (hold the tiller firm!, como 
ele intitulou um de seus ensaios metodológicos) em que a dimensão econômica e do sistema-mundo antecedem e, também por isso, acabam determinando as demais, quanto, e principalmente, pelas implicações que teria ao assumir que a dimensão política pode ser mais relevante do que ele admite na composição da dimensão econômica da economia-mundo. Por exemplo, segundo a abordagem do capitalismo oferecida por Jessop, a dimensão econômica do capitalismo é altamente entrelaçada e mesmo dependente de aspectos extraeconômicos para a sua configuração e para o seu funcionamento efetivo. Ou seja, uma análise acurada das categorias cruciais que fundamentam o capitalismo revela a incapacidade crônica deste sistema se autorreproduzir autonomamente, unicamente por seus próprios meios e a partir de seus próprios impulsos econômicos. Como argumentou Jessop (2002), "mercadorias" cruciais para o capitalismo, como natureza, trabalho, conhecimento e moeda (e se quisermos, outras relevantes como segurança, garantia dos contratos e da propriedade privada, controle das classes perigosas), não são mercadorias puramente econômicas, geradas, reconhecidas, produzidas e comercializadas como mercadorias comuns. Essas mercadorias dependem endogenamente em suas cadeias de valor de fatores extraeconômicos para a sua conversão em mercadorias. Necessitam que os Estados - com seus múltiplos aparatos - intervenham consistente e cotidianamente para que passem a operar na forma adequada ao capital. $\mathrm{O}$ capitalismo é um macrossistema que, para operar, depende de fatores políticos, cuja dinâmica primordial tem consistido em investir sobre (ou colonizar) o mundo da vida, a natureza e outros sistemas organizados sob outras racionalidades. Os Estados nacionais têm sido, pois, cruciais e indispensáveis ao capitalismo, mediando/ regulando essas investidas. O capitalismo não pode ser compreendido como um sistema que consegue funcionar sem a presença dos Estados, e essa dependência do capitalismo para com os Estados e para com a política é que torna a equação muito mais desafiadora.

A caracterização de Estado efetuada por Wallerstein torna-se demasiado simplista, quase mínimo: Estados pouco autônomos em relação aos interesses da burguesia mundial, que atuam movidos por uma ideologia liberal, e que praticam medidas essencialmente mercantilistas - de proteção contra concorrências indesejadas, e policialescas, de proteção contra as classes perigosas. Numa abordagem alternativa, e que considere a fundo os embates estruturais provocados pela onda longa de democratização como uma força ativa, pode-se compreender os Estados como relações sociais complexas que envolvem embates travados por forças sócio-político-econômicas razoavelmente articuladas em torno de programas e visões de mundo concorrentes, que embasam concertos sociais, por sua vez mediados por um conjunto de aparatos estatais e suas seletividades estratégicas. Ainda que as sociedades capitalistas e seus Estados dependam estruturalmente do bom andamento dos negócios privados, vai razoavelmente longe a distância entre o que os Estados e seus agentes públicos deveriam fazer para atender idealmente à agenda necessária do capitalismo e dos capitalistas daquilo que eles efetivamente querem ou conseguem fazer.

O conceito de Estado não pode ser simples porque as unidades de análise a 
que se referem não são simples, nem as disputas que nele se condensam, nem os resultados das suas ações estão previamente estabelecidos e seus impactos não unívocos. Ainda que a força do sistema econômico seja evidente e corretamente destacada por Wallerstein, por outro lado, a dependência, também estrutural e insuperável, que o sistema econômico capitalista apresenta da política, dos Estados e de suas políticas e instituições, representa a existência de espaços que estão sendo disputados politicamente. As pressões pela democratização ou de fechamento dos regimes seguem em aberto, e formam um vetor fundamental de possível redefinição das ações dos Estados em relação ao capitalismo.

Por fim, em suas formulações, Wallerstein dá a entender que não há maiores espaços para a escala nacional e para os tempos que não os de longa duração. Da perspectiva do que venho argumentando, é preciso considerar que, além dos importantíssimos ciclos ou tendências de longa duração, há movimentos políticos, econômicos e socioculturais que se desdobram e desfecham em períodos mais curtos, contados ao número de gerações, orientados para objetivos mais tangíveis e realizáveis, e que costumam ser conectados a movimentos e interesses mais abrangentes, mundiais e de longa duração, de liberdade como liberação. Se é correta a perspectiva de enfatizar o papel do sistema-mundo e das cadeias de valor mundial, também parece ser relevante incorporar tempos, como os geracionais e escalas, como a nacional, regional e local, nos quais projetos alternativos de desenvolvimento econômico e social costumam florescer, degenerar ou vigorar em embates políticos que não podem ser presumidos de antemão como autoenganos, nem completamente desconectados das disputas sistêmicas mundiais. Tempos, escalas e questões que deveriam compor de forma mais vigorosa o espectro de análise das ciências sociais que pretenda vigorar no século XXI.

\section{REFERÊNCIAS BIBLIOGRÁFICAS}

ACCO, Marco Antonio (2009) Para onde vão os Estados Nacionais? Perspectivas da Teoria Social Contemporânea sobre as Pressões para as Transformações dos Estados Nacionais na virada para o Século XXI. Campinas: Unicamp/IFCH, Tese de Doutorado.

ARRIGHI, Giovanni (2008). Adam Smith em Pequim: Origens e Fundamentos do Século XXI. São Paulo, Boitempo.

ARRIGHI, Giovanni, Beverly Silver et al. (1999) Chaos and Governance in the Modern World System. Minneapolis, MN: University of Minnesota Press.

BRAUDEL, Fernand (1996). Civilização Material, Economia e Capitalismo - Séculos XV- XVIII. (Vol. I) Trad. Selma Costa. Ed. Martins Fontes.

BRESSER-PEREIRA, L. C. (1998) Reforma do Estado para a Cidadania.: A Reforma Gerencial Brasileira na Perspectiva Internacional. São Paulo; Ed. 34; Brasília: ENAP.

BRESSER-PEREIRA, L. C. (1999) “Sociedade civil: democratização para a reforma do Estado". In Bresser-Pereira, L.C. Sola, Lourdes e Wilheim, Jorge (Org.) Sociedade e Estado em Transformação. São Paulo: Ed. Unesp; Brasília: ENAP.

CABLE, Vincent (1995) The Diminished Nation-State: A Study in the Loss of Economic Power. Daedalus, 124 (Spring).

DOWBOR, Ladislaw (2016). "Políticas urbanas e participação: o resgate da democracia pela base". In Balbim, Renato, org. Geopolitica das Cidades: Velhos Desafios, Novos Problemas. Brasília: Ipea. 
EVANS, Peter B. (2008) "In search of the 21 century developmental state”. In CGPE Working papers. no 4 - Centre for Global Political Economy. Sussex University. November.

EVANS, Peter (1997). "The eclipse of the State: Reflections on stateness in an era of globalization". World Politics 50 (1): 62-87.

EVANS, Peter B. (1995), Embedded Autonomy: States and Industrial Transformation. Princeton, NJ: Princeton University Press.

EVANS, Peter, D. Rueschemeyer, and Theda Skocpol, eds. (1985) Bringing the State Back In. New York: Cambridge University Press.

HELD, D., McGREW, A. Glodblatt, D. e Perraton, J. (1999) Global Transformations - Politics, Economics and Culture. Stanford: Stanford University Press.

HELLEINER, Eric. (1996) States and the Reemergence of Global Finance - From Bretton Woods to the 1990s. Ithaca: Cornell University Press.

HIRST, Paul, and Thompson, Grahane. (1996) Globalization in Question. Cambridge: Polity.

JESSOP, Bob. (2002) The Future of Capitalist State. Cambridge, UK: Polity Press.

LAIDLER, John (2015). “What's really happening to global violence rates?” World Economic Forum. https://www.weforum.org/agenda/2015/11/whats-really-happening-to-global-violence-rates/ Último acesso em fevereiro de 2018.

LEANDER, Anne. (2004) "War and the un-making of states: taking Tilly seriously in the contemporary world. In GUZZINI, Stefano e JUNG, Dietrich, eds. Contemporary Security Analysis and Copenhagen Peace Research. London: Routledge.

MANN, Michael. (1997) "Has globalization ended the rise and rise of the nation-state?" Review of Internacional Political Economy 4:3 Autumn 1997: 472-496

MARKOFF, John (2013) "Democracy's past transformations, present challenges, and future prospects". International Journal of Sociology, vol. 43, $\mathrm{n}^{\circ} 2$.

MARQUES, Luiz (2015) Capitalismo e Colapso Ambiental. Campinas, Editora Unicamp.

MORGENTHAU, Hans J. (2003) A Política entre as Nações: A Luta pela Guerra e pela Paz. Brasília: Editora Universidade de Brasília/Instituto de Pesquisa de Relações Internacionais; São Paulo: Imprensa Oficial do Estado de São Paulo.

NOGUEIRA BATISTA Jr., Paulo (2007). “Nacionalismo e desenvolvimento”. Novos Estudos Cebrap 77 Mar. 2007, pp. 29-35.

NOGUEIRA BATISTA Jr., Paulo (1998). “Mitos da globalização邓”. Estudos Avançados USP 12 (32), pp. 125-186.

OHMAE, Kenichi. (1996) O Fim do Estado-nação: A Ascensão Das Economias Regionais. Rio de Janeiro: Campus.

PAULA, A. P. P. de (2005). "Administração pública brasileira entre o gerencialismo e a gestão social”. RAE-Revista de Administração de Empresas, v. 45, n. 1, jan-mar, p.36-49.

PIERSON, Paul (1994) Dismantling the Welfare State? Reagan, Thatcher, and the Politics of Retrenchment. Cambridge: Cambridge University Press.

PIRES, Roberto e GOMIDE, Alexandre (2014). "Burocracia, democracia e políticas públicas: Arranjos institucionais de políticas de desenvolvimento”. Brasília, Rio de Janeiro: IPEA, Texto para Discussão 1940.

POLLITT, C e BOUCKAERT, G. (2004) Public Management Reforms: A Comparative Analysis. Oxford University Press.

SANTOS, Boaventura Souza (2002). Reinventar a Democracia. Lisboa: Fundação Mário Soares, Gradiva.

SANTOS JR. Orlando (2015) Democracia e Governo Local: Dilemas da Reforma Municipal no Brasil. Rio de Janeiro, Letra Capital

SCHUMPETER, Joseph A. (1984) Capitalismo, Socialismo e Democracia. Rio de Janeiro Editora Zahar.

STRANGE, Susan (1996) The retreat of the State: the diffusion of power in the world economy. Cambridge: Cambridge University Press.

SUlEIMAN, Ezra (2003). Dismantling Democratic States. Princeton: Princeton University Press, 
TILLY, Charles. (1985) "War making and state making as organized crime". In Peter B. Evans, D. Rueschemeyer and Theda Skocpol, eds. Bringing the State Back In. Cambridge University Press.

WALLERSTEIN, Immanuel (2000a) “The end of what modernity?”. In WALLERSTEIN, I. The Essential Wallerstein. pp.454-471. Artigo publicado originalmente in Theory and Society, XXIV, 4, August, 1995: 471-488.

WALLERSTEIN, Immanuel (2000b) "Peace, stability, and legitimacy: 1990-2025/2050". In WALLERSTEIN, I. The Essential Wallerstein. pp. 435- 453. Artigo publicado originalmente in G. Lundestad, ed. The Fall of Great Powers: Peace, Stability and Legitimacy. Oslo: Scandinavian University Press, 1994: 331-49.

WALLERSTEIN, Immanuel (2000c) “Societal development, or development of the World- System?”. In WALLERSTEIN, I. The Essential Wallerstein pp. 112-128. Artigo publicado originalmente in International Sociology, I, 1, March, 1986, 3-17.

WALLERSTEIN, Immanuel (2000d) "The three instances of hegemony in the history of the capitalist world-economy”. In WALLERSTEIN, I. The Essential Wallerstein. pp. 253-263. Artigo originalmente publicado in International Journal of Comparative Sociology, XXIV, 1-2, Jan-Apr, 1983:100-108.

WALLERSTEIN, Immanuel (2000e) "The rise and future demise of the world capitalist system: Concepts for comparative analysis". In WALLERSTEIN, I. The Essential Wallerstein. New York: The New Press, pp. 71-105. Artigo publicado originalmente in Comparative Studies in Society \& History, XVI, 4, September, 1974, 387-415.

WALLERSTEIN, Immanuel (2000f) "America and the world: today, yesterday, and tomorrow". In WALLERSTEIN, I. The Essential Wallerstein, pp. 387-415. Artigo publicado originalmente in Theory and Society, XXI, 1, February, 1992, 1-28.

WALLERSTEIN, Immanuel (1999) "States? Sovereignty? The dilemmas of capitalists in an age of transition”. In SMITH, D. et al.(Eds.) States and Sovereignity in the Global Economy. London, NY: Routledge, pp. 20-33.

WALLERSTEIN, Immanuel (1984) The Politics of the World-Economy: The States, the Movements and the Civilizations. Cambridge: Cambridge University Press.

WALT, Stephen. (2002) “The enduring relevance of realism”. In KATZNELSON, I. and MILNER, H. V, eds.. Political Science - State of the discipline. New York: APSC: W.W. Norton \& Co: pp. 33-55.

WEISS, Linda. (1998) The Myth of the Powerless State. Cambridge, Polity.

WIMMER, Andreas. (2013) "States of war: How the Nation-State made modern conflict". Foreign Affairs November.

WRISTON, Walter B. (1989), “Technology and sovereignty”. Foreign Affairs, Vol. 67, No. 2, pp. 63-75.

WRISTON, Walter B. (1992). The Twilight of Sovereignty: How the Information Revolution is Transforming our World. New York: Scribner; Toronto: Maxwell Macmillan Canada; New York: Maxwell Macmillan. 